Política y Sociedad

ISSN: $\quad 1130-8001$

ISSN-e: $1988-3129$

\title{
Instrucciones y acciones instruidas ${ }^{1}$
}

Harold Garfinkel (1917-2011)

Traducción: Kenneth Liberman ${ }^{2}$ y Raúl Sánchez García ${ }^{3}$

Recibido: 22-12-2017/ Aceptado: 10-10-2018

\section{[en] Instructions and Instructed Actions}

Cómo citar: Garfinkel, H. (2019): "Instrucciones y acciones instruidas", (traducción de Kenneth Liberman y Raúl Sánchez García) Política y Sociedad, 56(1), pp. 213-234.

Sumario. I. II. Entornos perspicuos: una familia de términos. III. [Las Instrucciones] Como tópico etnometodológico. IV. La discapacidad visual como situación perspicua. V. Podemos hacerlo de nuevo: siguiendo instrucciones como la familiaridad alcanzable de los detalles.

Agradecimientos. Agradecemos las mejoras introducidas en la traducción por dos revisores anónimos de Política y Sociedad.

\footnotetext{
Capítulo Seis de El Programa de la Etnometodología por Harold Garfinkel.

2 University of Oregon (EEUU).

E-mail: liberman@uoregon.edu

3 Universidad Europea Madrid (España).

E-mail: raulsangar@gmail.com
} 


\section{I.}

Quiero hablar de forma aproximada sobre las instrucciones y las acciones instruidas. Permítanme comenzar con una sinopsis del argumento. No les quiero exponer un viejo argumento acerca de las instrucciones y de seguir instrucciones. En cambio, me voy a referir a algo que denomino "mi uso tendencioso de las instrucciones" y "mi uso tendencioso del modo de seguir instrucciones".

Que hable tendenciosamente es crítico en mi exposición. Con tendencioso quiero decir que me propongo hablar acerca de ellas con una tendencia firme y velada. Más aún, voy a saber de qué estoy hablando mucho antes de que les revele exactamente de qué estoy hablando. Y espero que finalmente lleguemos a un punto, tras haber presentado algunos materiales, en el que hayan visto, con sorpresa, que de hecho lo que tuve en mente todo el tiempo, y que será revelado al final, es de hecho lo que ustedes también tuvieron en mente todo el tiempo, salvo que yo tenía una versión contraria a la que podrían tener en mente. Y más que eso: verán que me propongo hablar hasta llegar al punto de un correctivo revelador acerca de lo que podrían tener en mente, llegando incluso a un correctivo radical.

Quiero ir hablándoles sobre en qué podrían consistir las instrucciones y el seguir instrucciones cuando hay algo más, otra cosa, algo diferente de estos maravillosos tópicos, algo ignorado y que posiblemente identifique más a las instrucciones y las acciones instruidas que lo que los estudios clásicos tienen en cuenta, hacen o jamás han tenido en cuenta o que, consideremos esa posibilidad, pueden tener en cuenta.

Cuando las instrucciones y las acciones instruidas se ofrecen a nuestras preguntas bajo estos auspicios, con lo que quiero decir que cuando no solo se habla de ellas, sino que se las especifica tendenciosamente, hablaré de ellas como un fenómeno radical. Por el momento usaré radical para referirme a ese qué más, qué otra cosa, diferente, ignorada, aunque identificada, ordinaria $y$ no disponible para los métodos más serios, técnicos y cuidadosos de los estudios clásicos con los que se las examina. Y para hacerlas observables mediante instrucciones.

Eso es lo que me propongo.

Permítanme esbozar los pasos de mi argumento.

Comenzaré recordando la distinción familiar entre instrucciones y seguir instrucciones; instrucciones $\mathrm{y}$ acciones instruidas, instrucciones $\mathrm{y}$ acciones instruidas asociadas a ellas. Usaré corchetes [instrucciones] y «seguir instrucciones» para señalar las identificaciones comunes y corrientes que definen tópicamente a cada una de ellas y que mantienen su distinción.

Usaré esa manera de hablar del hecho de su disponibilidad para los métodos clásicos y de los infinitos modos vernáculos de hablar de las instrucciones; de la disponibilidad para nosotros de su carácter independiente, de la distinción entre ellas y, de este modo, de que plantean un fenómeno interesante para el análisis clásico.

Haré referencia a esta distinción como una distinción vernácula disponible: no hay que ir a la universidad para conocerla. Uno puede encontrar versiones cultas de 
estos ítems por separados, [reglas de investigación], [reglas-de-uso], pero culta o no, la distinción es con una frecuencia abrumadora una distinción vernácula.

Voy a proponer que eso puede ocurrir con las [instrucciones] y el «seguir instrucciones» - lo que con frecuencia es simplemente algo que obsesiona al analista - y no estoy hablando acerca del analista académico, no estoy hablando de los abogados o los ingenieros, no estoy hablando de los analistas profesionales, sino que estoy hablando de cualquiera que tenga razones para consultar instrucciones y entretenerse en la manera en que están siendo consultadas. También para entretenerse en la cuestión de cómo, cuando las instrucciones se introducen en el trabajo local de tener que seguirlas, pueden de este modo, tópicamente, plantearle al analista problemas de claridad o consistencia o completitud o de seguimiento o de adecuación factual, y que bajo esas circunstancias estas instrucciones y el trabajo de seguirlas que proponen, es decir, ofrecen, son una ocasión para, o le presentan al analista ciertas propiedades. Luego describiré algunas de estas propiedades, y las distinguiré como propiedades curiosas.

Son pistas de que hay algo respecto de las instrucciones y de seguir instrucciones tal que cuando, tópicamente, le ofrecen al usuario su carácter problemático (con respecto, por ejemplo, a la completitud o a su seguimiento o definición del sentido o la referencia que ahí proveen) sugieren que hay algo más, otra cosa, algo extraño, diferente a aquello con lo que los estudios clásicos son capaces de lidiar o a lo cual pueden llegar a tener acceso.

Voy a proponer que, al encontrar estas propiedades curiosas, las instrucciones y su seguimiento muestran en las ocasiones en que los métodos clásicos se usan para tratar, con sus virtudes y vicios, tópicos de claridad, univocidad, equivocidad, completitud - es decir, para tratar las incontables virtudes y vicios lógicos de sentido, orden, método, razón o racionalidad sin que ninguno de los tópicos que reúnen estos maravillosos rótulos sea excluidos de la posibilidad de ser elegido-, vamos a preguntarnos: ¿qué hemos hecho, etnometodológicamente hablando? ¿Qué estudios hemos hecho? Y ¿qué aprendimos de estos estudios que puedan sorprendernos? Hay más que lo que podríamos haber imaginado mediante el uso de los estudios clásicos requeridos más cuidadosos, respetables y técnicos. Como, por ejemplo, el método clásico de no comenzar nuestro estudio, o no avanzar mucho, antes de haber ganado nuestro derecho a continuar proponiendo una lista de definiciones terminológicas: "Por instrucciones entenderemos...", o diseñando representaciones genéricas de las prácticas y del trabajo que constituyen el seguir instrucciones.

Quiero llevarlos por cinco o seis entornos, "entornos perspicuos", entornos prometedores en los cuales hicimos algo etnometodológico. Entornos en los cuales introdujimos las políticas y los métodos de la etnometodología, examinando mediante la etnometodología algunos de sus objetos.

Luego preguntaré: ¿hay alguna manera en que podamos juntar estas propiedades curiosas con los casos - los entornos perspicuos, las cosas que hicimos - en los cuales había algo que aprender?

¿En qué consiste "juntar propiedades curiosas y casos"? Además, suponiendo que las juntemos, ¿Y qué? 
Quiero proponer que el "¿Y qué?" consiste en fenómenos radicales. Estos fenómenos radicales se dan en entornos perspicuos; de ningún otro modo, y en ningún otro lugar.

Entonces quiero concluir preguntando: bien, hay fenómenos radicales. ¿Y entonces? ¿Qué nos dice eso? ¿Qué hay que hacer? ¿Qué consecuencias tiene encontrar estos fenómenos radicales?

\section{Entornos perspicuos: una familia de términos}

Comenzaré explicando mi negativa a comenzar con definiciones. En vez de comenzar con definiciones, enunciaré una familia de términos. Propongo que nadie en su sano juicio debe alterarse por el hecho de que no comience con una definición de "instrucciones". En cambio, recomiendo que hagamos el truco heideggeriano. Se supone que, al comenzar su discurso sobre la metafísica, Heidegger habría dicho: en vez de comenzar con una definición de metafísica, en vez de preguntar "¿Qué es metafísica?", de modo que comenzáramos hablando acerca de la metafísica, en vez de eso haremos una pregunta metafísica, y de este modo aterrizaremos en medio de la metafísica.

Comenzaré con el truco heideggeriano. Propondré que la familia de instrucciones, que los miembros de esta familia, que cada uno de estos términos vernáculos nos recuerda que es un miembro que incluye las semejanzas —normas, directivas, regulaciones, leyes, órdenes, orden, reglas, criterios, planes, programas, asignaciones, mapas, manuales-, y que estas están disponibles en textos separables, es decir, [normas], [instrucciones], [mapas], [diagramas de cómo-haceresto]. Estas son algunas de las formas en que están disponibles. Cuando uno u otro están disponibles como un texto separable, lo denominamos versión "producto" de instrucciones, o versión "dócil". Usaremos [instrucciones] como un recolector y un recordatorio de que esta familia existe.

En contraposición, hay algo, también conocido vernáculamente como «seguir instrucciones». La idea es: si bien se pueden leer [instrucciones] sin tener idea de a qué van a parecerse en las ocasiones en las que uno tendrá que seguirlas, también pueden introducirse en entornos en los cuales, al ser seguidas, toman un sentido diferente y más vivo. Así es que en las ciencias sociales las diferencias, dadas por sentadas, son diferencias muy familiares entre aquello en lo que consisten las reglas si uno está leyendo reglas de un juego (digamos en el reverso del tablero) y aquello en lo que consiste ese conjunto cuando el tablero de juego está frente a uno $\mathrm{y}$ uno va a tener que jugar al juego que el seguimiento de reglas promete.

Así que tenemos las distinciones: producto/proceso; reglas/implementación de las reglas; reglas/reglas-en uso; asignación/proceso de asignación. Respecto a esta distinción, quiero proponer que puede ocurrir que estas reglas, estas instrucciones, puedan estar disponibles para alguien (hablaremos del analista) del siguiente modo: que las reglas sean de algún modo detalles de un entorno en, acerca de y a partir de las cuales seguirlas constituye el trabajo práctico, local, ocasionado que transforma 
las reglas en una descripción (un testimonio ${ }^{4}$ descriptivo) del trabajo en-curso, in vivo, de seguirlas.

Para ver de qué estoy hablando, consúltese la Muestra 1.

Es una hoja de instrucciones. Se cayó de una caja que traje de Builder's Emporium. La caja contenía las piezas de una silla. Estaban en el suelo de mi sala de estar esperando a que las montara. La distinción es clara: allí está la Muestra 1 cayéndose de la caja, antes de que yo vea nada de lo que está en la caja. Cuando miro la página veo: oh sí, diagramas $1,2,3,4,5 \ldots$ que se deben leer en serie; el diagrama de 2 es para su examen el que sigue al diagrama 1; tras la serie de los números que siguen, el diagrama 8 es legiblemente el último. Legiblemente antes que eso se habrá deslizado una cubierta sobre un marco de metal, y así sucesivamente. Ese es un texto dócil. El texto tiene un comienzo identificable; un ordenamiento serial de pasos en-curso; y un último paso al que apunta. Y así sucesivamente.

Ese es un texto dócil.

Ahora el resto de las piezas se caen, y mi mujer me advierte: por favor termina esa cosa antes de la noche; tenemos visitas. Ahora entiendo que esta hoja de cosas es en sí misma un detalle del trabajo que comienzo en el cual recojo las piezas y empiezo a encontrar, con las instrucciones, no lo que parece "lo primero", sino a lo que primero va a parecerse la cosa que estoy haciendo parecer.

Así, busco la pieza conectora del cuadro uno. Apenas veo el cuadro uno tengo el problema de ubicarme en el cuadro uno. ¿Ubicarme en la página? ¿En el cuadro uno? ¿Tengo todas las partes? En ningún lugar de la hoja dice: antes de comenzar, cuente las partes. Ni me aconseja que identifique las partes. Ni dice en-qué-consiste contar e identificar en qué consiste, qué es, a qué se llega como cuenta correcta, que parece haber sido correctamente sacada. Sí, estoy contando las piezas, pero también las estoy relacionando-con-el-diagrama-para-terminar-de-registrar-lassiguientes-cosas.

Ahora ven aquí a qué me refiero cuando propongo "el trabajo de seguir instrucciones" y propongo que, introducido como un detalle del trabajo de seguirlo, ahora encuentro las propiedades extrañas que tópicamente tiene esta hoja de instrucciones. ¿Cuánto se ha mostrado? ¿Muestra lo suficiente? ¿El asiento de tela encaja en el marco antes de que el marco de la silla esté ajustado a la pata?

$4 \quad$ El término original utilizado por Garfinkel es el de account. Los accounts son formulaciones exhibidas que consisten a la vez en dar cuenta y en dar explicaciones y que se refieren a la orientación de lo que está ocurriendo en esos momentos en ese entorno. Debido a las connotaciones tan específicas del término, hemos decidido introducirlo entre corchetes cada vez que aparezca en el texto original para recordar al lector el sentido de lo que expresa. [N. del T.] 
Muestra 1. Instrucciones para el montaje de una silla

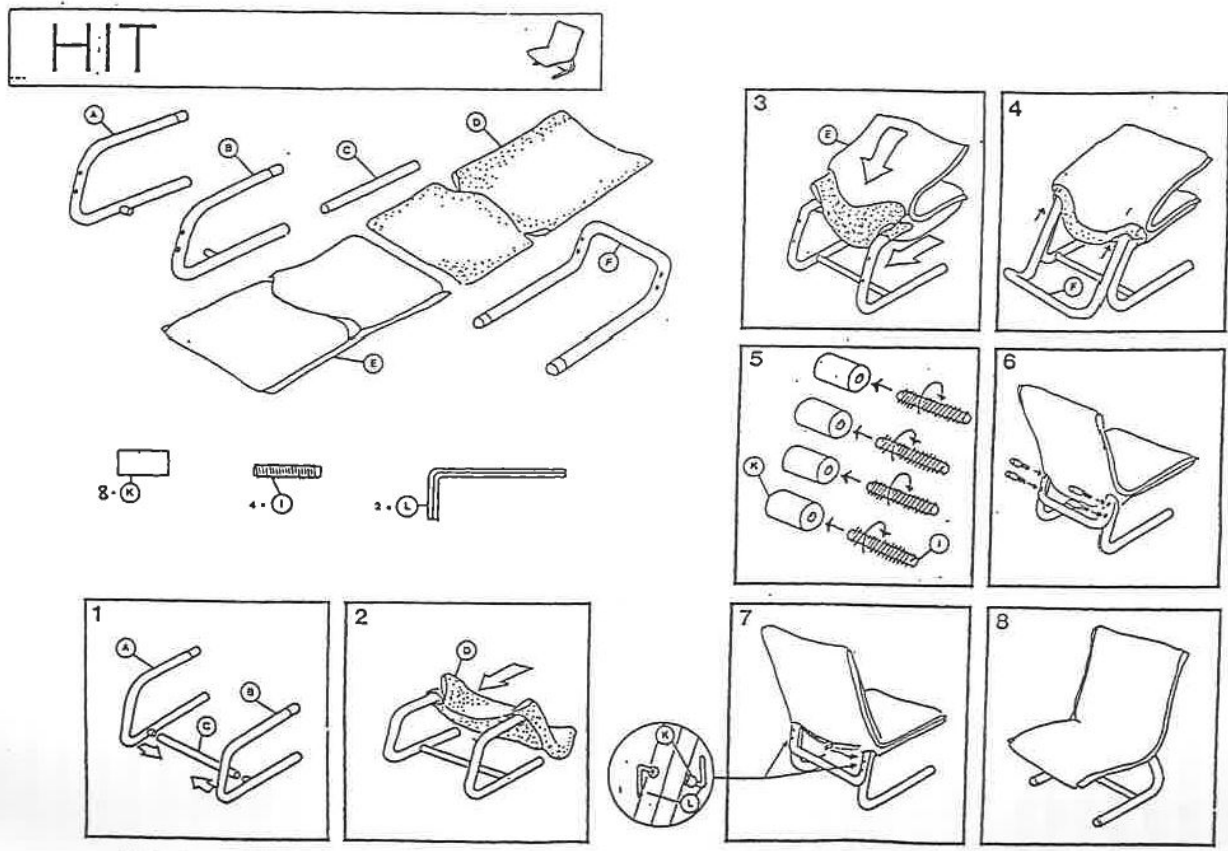

Fuente: Garfinkel, H. (2002): "Instructions and Instructed Actions", en H. Garfinkel, Ethnomethodology's program: Working out Durkheim's aphorism. Oxford: Rowman \& Littlefield Publishers, p. 201.

Consideremos el trabajo de llegar a ver que la abertura que en el diagrama aparece en la cubierta solo será vista como completada y fácticamente correcta cuando yo llegue a esa pregunta en el curso del armado tal y como lo haría la pregunta ¿exactamente-aquí exactamente-ahora ajusto los rieles a través de la cubierta? La respuesta práctica, visible como detalle en el diagrama propio de la silla es: no lo haga. Los cierres atraviesan los rieles de la abertura del tapete que aparece solo cuando los rieles se alinean SI, Y AHORA QUE, el tapete sin espacio de más ha sido encajado correcta y apropiadamente sobre el riel del asiento.

La adecuación factual, completitud, ambigüedad de expresión, capacidad de seguimiento, procedimiento efectivo, correspondencia singular de representación y objeto; estos tópicos, y todos los tópicos que encuentro además de estos, me están disponibles bajo la condición de que la topicalidad plantee el problema práctico in vivo en el que voy a tener que emprender y ocuparme no solo de "¿están completas las instrucciones?", sino, además, dadas las cuestiones de organización material a las que me enfrento por tener que terminar antes de que lleguen las visitas, de ¿a qué llegan a parecerse la completitud, capacidad de seguimiento, secuencia, secuencia correcta, historicidad local (y demás)?

$\mathrm{Y}$ esa es una pregunta etnometodológica. 


\section{II.1. Propiedades de la página de instrucciones}

Bajo esas circunstancias ahora encuentro ciertas propiedades de la página de instrucciones.

Primera. La Etnometodología se ha vuelto célebre por insistir en el carácter irremediablemente "situado" de las expresiones. Esto es un cliché. La idea es que - en lo que concierne a esta página con sus cosas - para que yo trate con la cuestión, visiblemente, in vivo, de si estas instrucciones están completas, ahora encuentro que estoy haciendo uso de lo que acabamos llamando "el método de la cláusula et cetera". Aquí está la página de instrucciones: hay esto y tantas partes, y se pueden leer como un conjunto, en este sentido serial, de izquierda a derecha, de derecha a izquierda, y así sucesivamente. Esto significa: cuándo y si debería producirse el leer la página para encontrar in vivo en la página, ofrecidos por la página, en y cómo las apariencias materiales de las partes tapizadas, los detalles significativos propios del diagrama para traerlos a la descripción de la silla que habrá sido armada, siguiendo las instrucciones mediante diagramas - que cuando encuentre, en caso de encontrar, una equivocidad del diagrama, puedo esperar que algo ocurra después, con lo cual posiblemente veré con lo que habré visto en qué consistió expresar mediante diagramas lo que estaba allí como relevante para ser visto todo el tiempo y que estaba visible allí desde el primer momento- glosadas como "disposición a esperar". Nuevamente glosadas como "aquí estoy, en el suelo de la sala de estar, produciendo una historia de ese proyecto y compartiendo en esa misma historia local que estoy haciendo con la cual encontrar en el curso de hacerla prospectivamente cuál es el sentido y la relevancia de la silla-representadaen-el-curso-de-su-montaje".

Tenemos, entonces, como letanía de propiedades, de cosas organizacionales de las que hemos hablado como propiedades de expresiones indexicales, como la propiedad de permitir que una expresión llegue a tener su sentido preciso y su referencia justa de acuerdo a dónde ocurrió o exactamente dónde ocurrió o exactamente dónde, en un in-vivo en desarrollo, en el trans-curso de un proyecto o de una historia personal, de un interés personal, de una biografía mutua con otros, etcétera, etcétera.

Al introducir estas especificaciones de expresiones, por ejemplo, "siéntese allí", obtenemos una letanía innumerable de expresiones indexicales para el caso exacto de la instrucción "siéntese allí".

Hemos reunido una cantidad de propiedades que las instrucciones podrían tener in vivo y que son de un modo tal que podríamos hablar de sus - de tratar con ellas - o en las prácticas usarlas o seguirlas - que las trataríamos- ¿cómo las llamaríamos? Llamémoslas ¿qué? Generalidades. El método de la cláusula et cetera es una de estas generalidades. No es que el método de la cláusula et cetera carezca de sentido o de referencia determinada, sino que uno nunca sabe, ni siquiera con et cetera, de qué diablos se está hablando, en el lugar de trabajo, acerca de lo que parece hasta que se topa con ello, por no hablar de lo que "realmente", "en realidad", "evidentemente", "comúnmente" parece, todo lo cual trae a colación el énfasis en la coherencia de los objetos lograda in vivo. Aun así, el et cetera ha hecho un magnífico trabajo. 


\section{II.2. La reflexividad como un fenómeno in vivo incrustado}

El método documental de interpretación genera cláusulas similares para la práctica de seguir instrucciones, donde la búsqueda in vivo con el documento en mano es la búsqueda del patrón subyacente a los detalles, el patrón que claramente está ahí, donde el patrón que está claramente allí es un ejemplo o un detalle de ese patrón y el trabajo de búsqueda con el documento es anticipar o construir ese patrón, "usar" el patrón para explicar el detalle como el detalle-del-patrón. Se puede hablar de ver el detalle-en-el-patrón o el patrón-en-el-detalle. Se puede hablar descriptivamente de ver el movimiento-en-el-juego o de ver el-juego-en-el-movimiento. Se vuelve una cuestión arbitraria: ¿qué es preferible?

El método documental de interpretación fue una manera de llamar la atención hacia las prácticas in vivo cuando estamos hablando de generalidades. La indexicalidad y el método documental de interpretación, ambos generalmente hablando, viajaban en compañía de generalidades. La reflexividad generalmente hablando era un compañero. Muchas vidas académicas se perdieron o fueron truncadas y atrofiadas por los cuidadosos intentos de proponer la reflexividad como nombre de un fenómeno general.

Pero ¿en qué podría consistir la reflexividad, generalmente hablando? Nadie estaría interesado en la cuestión general de la reflexividad. Estaría interesado exactamente en las maneras en las cuales una instrucción de $-\mathrm{y}$ a partir de- los detalles in vivo de su seguimiento asumía así su sentido o su referencia o su correspondencia con objetos, claramente, de hacer observable y explicable [accountable] el trabajo de seguirla; es decir, de encontrar, o revelar, o describir la tarea de seguirla. Así que lo que el término reflexividad quería decir era la manera en que se estaba haciendo aparecer a la instrucción, no de un modo parecido a sino como eso. No quería tratarse la reflexividad generalmente hablando. Quería saberse, como se dice, a modo de instrucción, si estaba irremediablemente incrustada en el trabajo vivido de seguirla y, en esa composición, ¿qué trabajo se está haciendo? Así es que se dice que un término que está haciendo in vivo el trabajo de describir, en la manera in vivo en que está haciendo el trabajo de describir, de ser reflexivo en la situación como un término reflexivo.

\section{II.3. Expresiones objetivas versus ocasionadas}

Quiero llamar la atención sobre otras propiedades. Siempre se está intentando hacer una distinción entre expresiones objetivas e indexicales in situ. En el suelo de la sala de estar yo habría estado buscando exactamente aquello que en esa página tiene un sentido definido que es indiferente al hecho de que está en esa página, dejando de lado que lo encontré en esa página en el suelo de mi sala de estar. Quisiera algo así como el sentido y la referencia trascendentalizados de las instrucciones que pudieran hallarse allí. Ese sentido que yo estaría buscando no tiene nada que ver conmigo; no tiene nada que ver con el ingeniero que diseñó este estúpido diagrama. Estoy buscando, estaría buscando, la claridad, y la consistencia, la verdad y corrección empírica, o cualquiera de los demás tópicos de la lógica, el sentido, la razón, el orden, o el método, de estas instrucciones generalmente hablando. Estaría buscando un método general para hacer determinables casos 
individuales en cuanto a su adecuación o cualquier otro escrutinio de estos y de modo tal que los detalles particulares del diagrama sean casos analizables en ciertos términos del método general.

Así pues, tengo un trabajo in vivo; un trabajo de tantos; ¿podré hacerlo?, ¿podré? ¿asignar a esas expresiones establecidas un sentido que estaba regido por reglas de interpretación tales que podría ser distinguido en los detalles de notación de ese diagrama respecto del sentido al cual su carácter localmente ocasionado requería que se lo encadenase?

Además de la distinción entre expresiones ocasionadas y expresiones objetivas, llamamos la atención, desde el principio, hacia la disposición del carácter sustituible de las expresiones objetivas por expresiones indexicales. Propusimos examinar el trabajo vivo de lo que era insistir sobre ese carácter sustituible. Era típico encontrar, especialmente en las ciencias naturales, aunque también en las ciencias sociales, la propuesta de que donde se produjesen expresiones indexicales podría sustituírselas por una expresión objetiva sin alterar, degradar, o evadir el sentido y la referencia trascendentalizados de la expresión.

Propongo que en el suelo de esa sala de estar se planteó, aunque solo como una posibilidad, que el carácter sustituible era una propuesta evidentemente realizable. No podía simplemente hacer la sustitución en cualquier caso real y mostrar efectivamente que, habiendo sido provista, la sustitución hubiera sido realizada. Así que aquí estaba, con esta distinción, y teniendo que proveer esa distinción, y teniendo también que proveer el carácter sustituible, teniendo que proveerlo en función de armar la silla para las cinco de la tarde; y topándome con la obstinación de esa página de cosas que prometía algo que no podía cumplir trabajando en ese suelo.

\section{II.4. Las propiedades in vivo de las [instrucciones] ${ }^{5}$}

Mencionaré varias propiedades más con la idea de terminar una enumeración de lo que voy a llamar las propiedades que tienen las [instrucciones] cuando, in vivo, nos ocupamos tópicamente con las tareas prácticas, realizadas de manera local y endógena, de la completitud, la consistencia, la capacidad de seguimiento, la corrección empírica, la univocidad, la determinación del sentido y la referencia, la secuencia temporal y la secuencia lógica, la identidad, la uniformidad en la notación, la comparabilidad, y lo demás, y llevamos a cabo nuestros asuntos con el uso de métodos clásicos. Uso el rótulo "métodos clásicos" para reunir las políticas de teorización natural, los métodos de análisis constructivo, y el uso de teorías lógicas establecidas con las que se hacen determinables y se determinan asuntos de adecuación cuestionable en relación con su "verdad" y "corrección".

Los mapas y los manuales tienen una propiedad maravillosamente incongruente de la cual los usuarios se quejan. De este modo, algunas quejas en las líneas telefónicas de atención a usuarios de software pueden ser así: "No veo qué estoy haciendo mal". "El manual no incluye mi problema". "No entiendo de qué habla el manual". Y estos son algunos ejemplos de soluciones: "No se puede entender solamente leyendo, y es prácticamente imposible decírselo". "Tiene que tener

El lector recordará que los corchetes indican que todavía estamos averiguando qué son las instrucciones. Así que todavía hay lugar para que el significado de las instrucciones crezca. [N. del T.] 
experiencia práctica". "No solo hay que leer el manual. Hay que leerlo junto a la consola mientras entiende qué quiere decir."

Las quejas apuntan al carácter incompleto del manual, su ambigüedad, su equivocidad, sus errores, sus equivocaciones, sus lagunas, sus omisiones, sus descripciones de maestro recalcitrante, su chapucería, sus mentiras, el uso de metáforas vagas, y el resto de incontables cosas de este tipo.

De manera recurrente, in vivo, los mapas y manuales les dan muestra a los usuarios de la incompetencia evidente del texto. In vivo, el manual le ofrece al lector de todo menos justo lo que necesita. El modo en que el texto nos falla, justo la cosa que uno quería de él, lo que hay que tener, ahora, justo aquí, en el punto justo en que uno está en su proyecto; ese problema seguro que estará allí esperándote, pero no hay en el mundo forma de preespecificar las condiciones bajo las cuales se va a introducir en tu isla local de orden. Esto significa que hay que estar en plena acción y justo allí, justo porque y justo del modo en que uno necesita más que nada en el mundo justo esto del texto y que está en eso y en la manera en que uno lo quiere y lo necesita, es eso lo que uno no puede tener.

Me voy a referir a estas propiedades como propiedades curiosas. Uso curiosas como un coleccionista. Quiero decir primero que estas propiedades están disponibles masivamente. No es que había una vez, tiempo atrás, bajo una piedra, en la India, algo que, si uno miraba en la dirección correcta cuando la luz daba bien, podía captar de un vistazo. No. Más bien estas propiedades son siempre inevitables. Dondequiera que uno esté ocupado in vivo en encontrar y seguir instrucciones, seguro que ALLÍ es donde estas propiedades serán dadas. ALLI es donde uno las encontrará en realidad y no supuestamente, de verdad y evidentemente y cotidianamente; en esto consiste encontrarse trabajando en reconocer y seguir instrucciones.

Así que, digamos: en primer lugar, ocurren masivamente. "Masivamente" es demasiado débil. Necesitamos algo del orden de la abundancia celestial, y por lo tanto más allá de la cantidad, porque la cosa organizacional etnometodológicamente interesante es que estas propiedades son inevitables, irremediables $y$ son comunes y corrientes.

Estas propiedades son ordinarias. Hay que apreciar esto. Son cotidianas. Son vulgares en el mismo sentido en que ser competente en la calle es una competencia vulgar. La competencia no es nada especial; no es nada que haya que celebrar o de lo cual uno pueda darse la enhorabuena o jactarse; no es nada únicamente ni singularmente de autoría propia y, sobre todo, lo sabe todo el mundo. No hay que ser alguien en particular que haya ido a la universidad y ahora puede verlo. Sino que, si uno se enfrenta a esto, entonces esto es lo que uno sabe acerca de las instrucciones y del trabajo de seguirlas.

Así que quiero remarcar que ocurren masivamente y que son inevitables e irremediables. Sí, se hacen, se pueden hacer y están dadas sin nada oculto, sin pasarlas por alto, sin aplazamiento, evasión, ni tiempos muertos y están, se presentan, en y como muestras de competencia vulgar. Las reúno bajo el término "curioso".

Hay más que eso en estas propiedades que reúno usando el término "curioso".

En aquellas ocasiones en las que uno puede atreverse a llamar la atención del instructor hacia el hecho de que las instrucciones y el seguimiento de instrucciones 
tienen estas propiedades curiosas, en cada caso esto es lo que uno encuentra. Hablo aquí rotundamente. No digo quizá. No estoy hablando de forma actuarial. No estoy proponiendo que hay una probabilidad. No digo que esto ocurra con una frecuencia. No estoy haciendo una observación sobre una disposición. Estoy proponiendo: en cada caso real sin falta, si uno presiona al preguntar, "Señor, ¿podría prestarle atención a esto que ocurre con ellas?”. Entonces en ese punto uno encontrará lo que Melinda Baccus identificó como: “Ah, bueno, sí, aquí no, ahora no, todavía no, espera un poco más". ¡Y eso no es una crítica! No estoy hablando irónicamente. No me estoy burlando. No estoy diciendo: "Vean la impostura de los estudios sobre instrucciones", sino que quiero hablar de algo que es asombroso y bello, que es algo de lo cual, entiendo, habló Merleau-Ponty como de los milagros familiares de la sociedad cotidiana. ${ }^{6} \mathrm{Y}$ aquí nos encontramos con un milagro familiar. Obviamente es un milagro, una cosa milagrosa: Bueno, sí, así ocurre. No me pregunten, yo no sé. Nadie sabe, ocurre así sin más. Es ese tipo de apreciaciones sobre su carácter de dación. ${ }^{7}$

Así que tenemos la propiedad adicional de que está dado que, respecto de estas propiedades, las instrucciones son problemáticas. Esto quiere decir que se ofrecen a sí mismas a los proyectos de clarificación, de elucidación, de elaboración de las grandes iniciativas que la investigación promete hacer con $-\mathrm{y}$ que se les hará alas instrucciones. Y en todas esas iniciativas, en todas esas promesas, no solo son problemáticas; son intratablemente problemáticas. No se prestan a lo que uno quiere de ellas en la investigación simplemente porque uno sea muy inteligente, o porque uno tenga los amigos adecuados, o dinero, o porque lo necesita para el viernes. Así que son intratablemente problemáticas.

No solo son inevitables y comunes y corrientes, sino que también lo son esencialmente. Todo intento de remediarlas, todo intento de evitarlas, usará los mismos recursos usados para demostrar que han sido remediadas o evitadas.

\section{III. [Las Instrucciones] Como tópico etnometodológico}

Dadas estas propiedades de las instrucciones y del seguimiento de instrucciones y dado que estas propiedades son propiedades curiosas en las ocasiones en que estas propiedades se les presentan al usuario como problemáticas, como tópicas en el sentido que he propuesto; ¿hay algo que etnometodológicamente podamos hacer? ¿Hay entornos que podamos examinar con los cuales hallar ese más, eso otro, diferente, ignorado, y sin embargo identificatorio de las instrucciones y su seguimiento, que el más riguroso, técnico, cuidadoso y diestro método clásico usado haga disponible? ¿Podemos retomar estas propiedades curiosas y encontrar situaciones del mundo real en las cuales, o en y como las cuales, aprender qué más hay en las instrucciones que lo que efectivamente ofrecen, lo que alguna vez han ofrecido o lo que pueden ofrecer los métodos clásicos?

Maurice Merleau-Ponty, The Visible and the Invisible, ed. Claude Lefort, trans. Alphonso Lingis (Evanston, Ill.: Northwestern University Press, 1968), 170. Versión en español: Maurice Merleau-Ponty, Lo visible y lo invisible: seguido de notas de trabajo, ed. Claude Lefort (Barcelona: Seix Barral, 1970).

Véase Husserl, Ideas I. [N. del T.] 


\section{III.1. Lentes de inversión}

Las lentes que invierten la visión hacen disponibles los campos fenoménicos de las tareas humanas ordinarias como detalles revelados de manifestaciones evidentes y examinables. Con ellas encontramos las propiedades de los detalles vividos, fenoménicos de las instrucciones y de las acciones instruidas, y encontramos que esos detalles están encadenados a la irremediable encarnación de las personas en ese entorno.

Muestra 2. Lentes de inversión
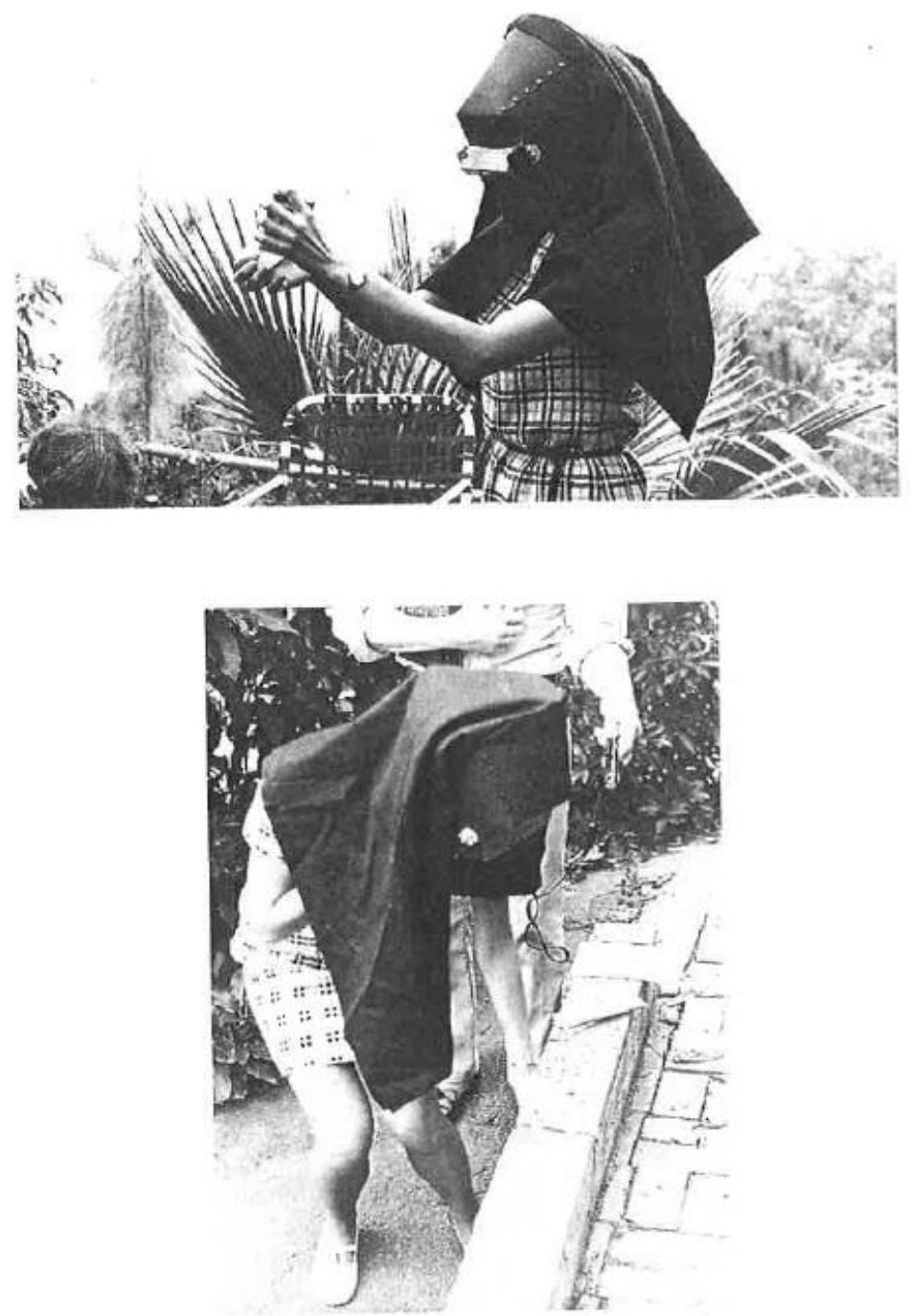

Fuente: Garfinkel, H. (2002): "Instructions and Instructed Actions", en H. Garfinkel, Ethnomethodology's program: Working out Durkheim's aphorism. Oxford: Rowman \& Littlefield Publishers, p. 208. 
Las lentes hicieron posible examinar estas tareas en y como detalles de la acción práctica alcanzadas quiasmáticamente, de manera estable, común y corriente, en y como detalles contundentes y coherentes.

Las lentes se fijaron en cubos de basura que, puestos boca abajo, se usaron como máscaras. Las lentes también se montaron y usaron en máscaras de soldador, tal como se muestra en las fotografías.

Los cubos se apoyan sobre los hombros; los prismas se colocan al nivel de la mirada. En esa posición la escena se invierte. Mientras usan las máscaras los estudiantes intentan realizar tareas ordinarias, triviales incluso. Por ejemplo, mando a un grupo al baño de mujeres y al baño de hombres donde hay lavabos. Cada estudiante tiene una taza de plástico. Cada uno tiene que llenar la taza. Tienen que ver, por sí mismos, el seguimiento de sus propios "quehaceres" y con o sin la máscara, mirarse unos a otros "ocupándose" de llenar la taza.

En la foto Maryann tiene puesta la máscara. Ella y Jerry están en el jardín del fondo; tienen el muro al costado. Jerry le ha dicho: "Maryann siéntate allí". Hace este gesto (señala): "Maryann siéntate allí". Maryann, con las lentes puestas, dice: "Puedo ver a Jerry, pero no sé dónde está".

En la foto ella está al lado de la pared; después de que Jerry diga eso ella gira hacia la pared y hace esto (palmea la pared); mientras palmea la pared pregunta: “¿Aquí?”; él dice: "No”. Ella palmea: “¿Aquí?”. "No”. Ella no lo mira. Palmea: “Aquí?”. "Sí". Palmeando la pared trata de encontrar lo que no puede encontrar cuando va buscando encontrar a Jerry y ve a Jerry señalando el lugar donde ella debería sentarse. Así que aquí tenemos una primera cosa que surge acerca de qué es encontrar la inteligibilidad y al buscar y mirar a algo escuchado y oído, encontrar la capacidad de seguimiento de una instrucción como la cosa más ordinaria del mundo.

Al llegar a una fiesta, la anfitriona te recibe: "Por favor siéntate", y hay un gesto de bienvenida. Lo que Maryann no puede ver es lo que Jerry hace con sus ojos y que hace reconocible, cuando ella busca aquello, el hecho de que sus ojos en una mirada analizable tienen un destino. Además, no puede ver cuando él señala que el señalar es un gesto que ella trata de seleccionar en un conjunto de detalles fenoménicos que pueden examinarse para encontrar la dirección de la señal, y que la dirección misma tiene un destino que es posible seguir y encontrar. Ella no puede ver desde donde está que, al final de una pared, a su costado, se ubica Jerry y que allí se lo puede ver enfrente de ella en relación con la pared que corre de costado a la derecha de ella y a la izquierda de él. Con el uso de las lentes encontramos aquí esta colección de ¿qué? Los glosaremos como propiedades direccionales y orientadoras - de camino, pared, muebles, cuerpos, cabezas, rostros, brazos, "quehaceres sonoros", manos, dedos, mirada - glosados y así no vistos ni visibles de nuevo como el "entorno del jardín". Estas no son propiedades euclidianas. Son detalles de un campo fenoménico. Para obtenerlos, hay que tener personas encarnadas allí e involucradas de manera encarnada en tareas comunes y corrientes. Esas propiedades han escapado a la insistencia del análisis formal: "Después de todo, ¿qué son las estructuras invariantes de esas propiedades? Queremos no ser desbordados por una colección que conforma la circunstancialidad de las actividades ordinarias". 
Pero las lentes de inversión nos revelan que en efecto hay un invariante. Hay una estructura en esos detalles fenoménicos. Hay constancias. Pero no han de encontrarse introduciendo representaciones genéricas en el flujo in vivo de las prácticas. En cambio, son aportadas endógenamente por los partícipes locales, que son el personal que está trabajando en producir los fenómenos realizados. Y porque son aportadas así, deben, de algún modo, ser descubiertas, endógenamente, por nosotros.

¿Es esta nuestra especulación? Por el momento diremos que sí. La especulación es superada cuando nos preguntamos: “¿Qué hacen las lentes?”. “¿Para qué sirven las lentes?".

Las lentes socaban, destruyen, hacen completamente indisponible el conocimiento adquirido y la coherencia conocida de los detalles fenoménicos. Así es como se tiene que ver eso. Cuando uno se pone las lentes en los ojos, la escena se ve así: "Está bien, ¿y qué? Es el mismo cuarto familiar solo que está al revés". Pero, cuando uno intenta hacer algo con la escena que nos parece tan familiar, encuentra que uno es un inepto. Uno encuentra que la escena, los trabajos que la escena familiar "solicita" son intratables. No es que uno no pueda de algún modo tratar su escritorio desordenado invertido como un problema a resolver, sino que, al tener que hacer eso, uno se ocupará de codificar ese desorden familiar, aunque al revés, de la manera de reespecificarlo para lo que sea, por ejemplo, encontrar un lugar para sentarse y ver el montón desordenado de manera tal que para uno y para Cualquiera, la disponibilidad del montón al acceso privilegiado de la mano derecha a la pila - que contiene pero que no esconde la carta hacia la cual va la manoesté cargada en su inevitable y solo ahora examinable curso "técni-co".

Así, una primera colección de cosas que aprendimos con las lentes es la relevancia masiva de la coherencia realizada de los detalles fenoménicos de las tareas encarnadas. Estas son actividades prácticas. Piénsese estas tareas como cuerpos; no los cuerpos de los anatomistas, ni de los biólogos, sino cuerpos que hacen el trabajo. Los cuerpos de las prácticas. Estos cuerpos tienen ojos que son habilidades; ojos que son habilidades en los modos en que los ojos hacen el trabajo de mirar. Cuando ver es algo más, otra cosa y algo distinto de la posición de las órbitas descriptible formal y analíticamente para asegurar cierto registro retiniano de un campo perceptivo, por no hablar de un campo visual.

Con las lentes aprendimos acerca de la coherencia realizada de un campo fenoménico, de los detalles de las posiciones y ubicaciones: el trabajo posicional de partes del cuerpo como dedos, ojos, pies, cabezas, labios, mentones. Las lentes son recursos que, al socavar el detalle coherente realizado transparentemente de los trabajos indispensables, nos dan lo que necesitamos de nuestro proyecto, que es volvernos nuevamente extraños a los modos de la acción práctica como cosas mundanas.

\section{III.2. Jugar al ajedrez con lentes de inversión}

Hay otra colección de cosas organizacionales que puede ser revelada con lentes inversoras de la visión. Aprendimos jugando al ajedrez con lentes de inversión que los lugares manifestados-del-juego, las ubicaciones-evidentes-del-juego, laspiezas-del-juego, no podrían ser vistas solo conociendo las reglas del juego. En 
cambio, en los lugares donde el juego se estaba manifestando de manera evidente como un campo fenoménico de piezas, uno ve allí las razones-para-una-pieza, y la razón-en-las-piezas. Las lentes hacían imposible ver eso y hacerlo en el tiempo dado para el trabajo de ese reconocimiento en y como el tiempo propio de y previsto para una jugada-del-juego evidente para todos. Uno no tenía todo el tiempo del mundo para descifrar en el ejercicio de codificación exactamente qué es lo que iba a hacer a continuación. Más aún, uno no podía abordar ni mucho menos hacer disponible lo que un siguiente movimiento, en-y-como-el-juego, en lo que consiste, podría haber hecho parecer en su detalle coherente. El tiempo que llevó llegar a la pieza, con un gesto rápido, moverla de aquí hacia allí, llegó a ser una cualidad constituyente de la propiedad del movimiento: que el movimiento fuera legal; que al hacerlo uno ofreciera así, de un modo evidente para todos, esto: acerca de la jugada que uno sabía que estaba haciendo. Se podría ver que uno sabía lo que estaba haciendo.

Un jugador no se mete en la cabeza del otro. En vez de eso, ve en el gesto todo el sentido, el objetivo, el propósito, el plan, y lo que se tiene en mente (clara o equívocamente) en lo que parece. Cuando se usan lentes de inversión, como los detalles fenoménicos se pierden, todo eso se pierde. Uno tiene en cambio un sentido del estado presente del juego; un sentido de una posible jugada del juego, un sentido de detalle fenoménico, un sentido de campo fenoménico, pero no el estado presente vivido del juego, la posible jugada vivida, el detalle fenoménico vivido; es decir la jugada, la jugada real, efectivamente, evidentemente y todo ello de manera cotidiana.

La principal pérdida implica que ahora se vuelve accesible a nuestro examen inspeccionable. El uso de lentes inversoras de la visión nos proporciona una perspectiva por incongruencia. (Tomo la frase de Kenneth Burke). ${ }^{8}$ Introducen un creador de problemas heideggeriano en las tareas humanas ordinarias. Las prácticas que se han vuelto encarnadamente transparentes en su familiaridad —en la familiaridad de una habilidad - ahora se vuelven examinables de nuevo. Las lentes de inversión como creadores de problemas son sumamente instructivas a este respecto.

No plantean el problema para la Etnometodología y carecen de interés para la Etnometodología al plantear la cuestión de si las personas pueden resolver los problemas que introducen. Usarlas para eso no es mucho más que psicología experimental a lo Mickey Mouse. Usamos lentes de inversión como una forma de hacer análisis, etnometodológicamente. Las lentes se usan para concentrarse en las apariencias coherentes de Las Cosas producidas endógenamente. La idea es esta: los objetos mundanos, como la contundencia y la cohesión de los detalles, están disponibles en las apariencias de Las Cosas organizacionales. Si no, entonces, ¿dónde más en el mundo las va uno a encontrar? Etnometodológicamente, son dadas en un despliegue instructivamente observable de detalles aparentes; de detalles en y como su coherencia proporcionada productivamente.

La idea no es buscarlas en la cabeza de nadie. No hay nada en las cabezas más que cerebros. Si uno busca en las cabezas eso no ayuda para nada. Uno continúa con la empresa de inventar vid-entes, inventar jugadores, inventar actores, inventar lectores, inventar niños, cuando no es eso lo que se le pide ni es lo que uno quiere 
hacer. Lo que uno quiere hacer es encontrarse en medio de sus actividades vividas y bajo esos auspicios proceder a revelar, elucidar, iluminar y hacer observables instructivamente sus demostraciones presenciables como detalles revelados de sus demostraciones locales: exactamente lo que están haciendo que sea así examinablemente. Y examinablemente en este caso, que el sociólogo trascendental, experto en comunicaciones trascendentales, con el ojo en la cerradura: "No me pregunten; no sé nada. Solo estoy mirando". No es eso. Es algo curiosamente diferente a eso en gran medida. Ese algo implica que uno es testigo de estos asuntos de la misma manera en que uno es competente para empeñarse en sus prácticas. Y esa es una política distintiva de la investigación etnometodológica. Recomendar como un procedimiento de trabajo, como una máxima de trabajo, la política de trabajo de que uno debe ser competente en las prácticas que examina si va a haber la más mínima posibilidad de encontrarse con fenómenos contundentes, reproducibles de manera inspeccionable e instruible, en los que consiste el ser testigo de.

\section{La discapacidad visual como situación perspicua}

\section{IV.1. La Cocina de Helen}

Unos pocos casos más pueden darles una mejor idea acerca de qué tratan las situaciones perspicuas como tópicos etnometodológicos. He tenido varios estudiantes que de una manera u otra padecían ceguera.

La muestra 3 es una foto de la pared de la cocina de mi estudiante Helen. Fue tomada en su cocina hacia el final del verano previo al otoño en que se iba a casar, cuando se estaba preparando para recibir a su marido, una persona con visión normal, que se iba a mudar a su apartamento. Anticipando las recetas que estaba preparando para complacerlo, tuvo que pasar el verano preparando una receta tras otra y resolviendo para cada una de ellas dónde se encontraría cada utensilio, cada ingrediente, exactamente cada cosa en la nevera y en la alacena, exactamente dónde, ítem por ítem, se encontraría el siguiente ítem en una secuencia en desarrollo y dónde encontrándose sería tomado, transportado a un área de recolección y dónde dentro del área en que estaban colgados se ubicaría de manera tal que pudiera concentrarse en cada uno de ellos para los últimos pasos que completan la receta.

Helen padecía ceguera nocturna congénita. Si uno hace un anillo apretado con el índice contra la articulación del pulgar y orienta ese círculo hacia la pared de enfrente, ese pequeño halo de luz es lo que Helen tenía como campo visual utilizable. Esto quería decir que Helen hacía muchos barridos. Nunca terminaba de hacerlo. Si tenía que ir a la nevera, no era como si pudiese captar de un vistazo lo que había ahí y dónde estaba, sino lo que estaba disponible era lo que podía alcanzar y encontrar. Tenía que hacer esto (mover la cabeza hacia atrás y hacia adelante) para registrar el interior y el contenido allí ubicado. El problema de Helen era el cómo tomar una docena de recetas y preparase para hacerlas como platos que consisten en vivo en una secuencia instruida de cómo hacerlas, donde la secuencia instruida era de este tipo: tenía que lograr la transparencia del trabajo encarnado. 
La transparencia quería decir que durante el verano tenía que llegar a lograr esto: para los espagueti, ubicarse de modo tal de asegurarse un alcance simétrico para ambos brazos a fin de que las manos al alcanzarlos se dirigieran irreflexivamente hacia los ingredientes que habían sido colocados con una orientación que los hacía fácilmente accesibles en una organización por intervalos de alcance al frente y a los costados, trayendo primero esta olla y este paquete de este estante, cronometrando el acarreo como para apoyarlos lado a lado, el espagueti a su izquierda, la olla disponible a un giro cómodo debajo del grifo después de coger los espaguetis, levantarlos, romperlos en la olla, y así sucesivamente. Y esto tan solo con una enumeración y una serialización "normalmente irreflexivas", pero sin barrido. Así podía reservar fuerzas para contingencias que escaparan a la serialidad local y momentos ocasionales de omisión, innovación, improvisación, sustitución.

Muestra 3. La pared de la cocina de Helen

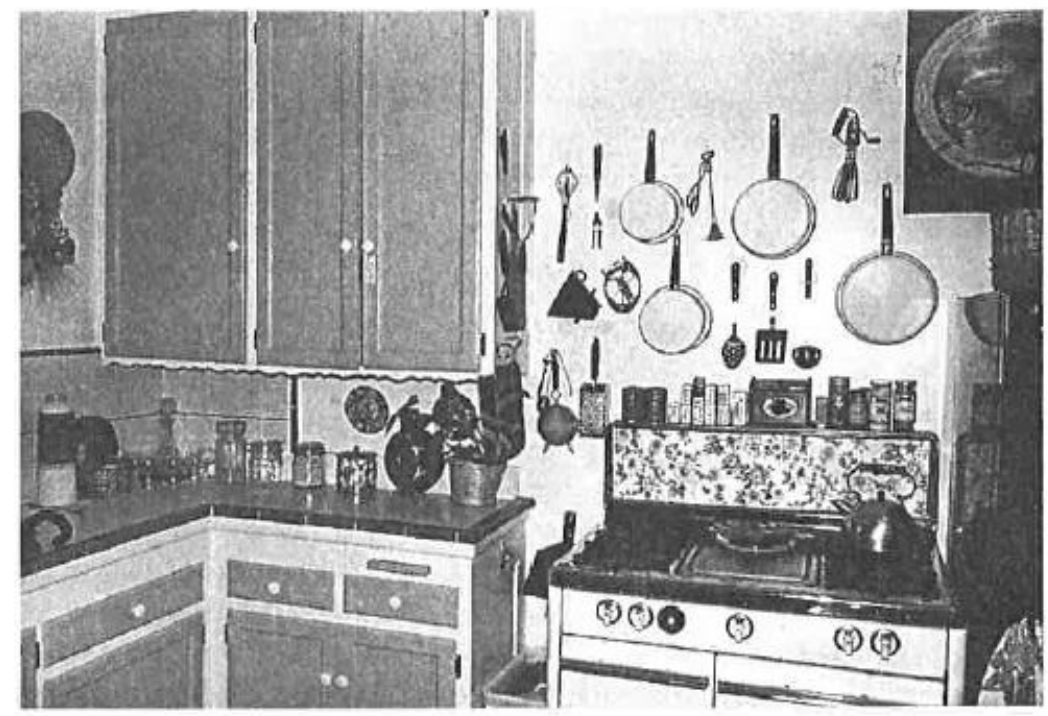

Fuente: Garfinkel, H. (2002): "Instructions and Instructed Actions", en H. Garfinkel, Ethnomethodology's program: Working out Durkheim's aphorism. Oxford: Rowman \& Littlefield Publishers, p. 213.

En esta pared se ve un testimonio [account] residual del trabajo del verano. Receta tras receta, Helen convertía los platos en actividades realizadas transparentemente, encarnadas, personalizadas, analizables localmente, historizadas localmente, y regidas por reglas. Cada una de ellas era un plato. En el caso de los espagueti, por ejemplo, todas estas se dan como espaguetis, espaguetis concretos, espaguetis en y como detalles quiasmáticamente contundentes y coherentes. Helen nos enseña eso.

Las personas que ven esa pared a veces remarcan la pulcritud del orden. Lo cual, por supuesto, para la etnometodología no es ninguna novedad. No tiene nada que ver con la historia de esa pared. Ni puede demostrarse esa pared, mucho menos reproducirse, mediante un análisis clásico de esa pared; por ejemplo, Giddens, la semiótica, el manual de Genensky, los factores humanos, etc. 
No se sabe qué está pasando con esa pared hasta que, a menos que $-\mathrm{y}$ solo y exactamente en el caso real de que- Helen esté preparándole tocino y huevos a su marido. La ceguera es una situación perspicua de la cual aprendemos cosas. La pared de la cocina de Helen es un caso de lo que hicimos y lo que aprendimos. Es un caso de fmétodosł de investigación etnometodológica. Es un caso de "introducción de la etnometodología en la cultura local de la cocina de Helen, de examen (desde dentro de esa cultura) de varios de sus objetos".

\section{IV.2. Los discapacitados visuales como instructores de las personas videntes}

Otra estudiante ciega, casada, hizo varias fiestas en su casa, de las cuales me habló, y para una de las fiestas hizo una grabación de toda la noche, comenzando antes de que llegara el primer invitado y apagando el aparato después de que se fuera el último.

Esta es una de las cosas que grabó y me dijo que era algo que se repetía en sus fiestas: De pie al lado de la puerta, cuando llegaban los invitados, les decía: "No te quiero en mi cocina. Por favor mantente fuera de mi cocina". Un extraño saludo, tal vez, y una instrucción comprensiblemente enfática. La idea: las personas videntes que llegan al lugar donde ella tiene que trabajar le cambian de lugar las cosas, ayudándola sirviéndose ellos mismos, por ser encarnadamente hábiles y normalmente irreflexivos. Estoy hablando de detalles fenoménicos. Claire llega, tiene sed, abre la vitrina donde están los vasos, toma el vaso, abre el grifo, bebe y pone el vaso boca abajo. Tras un rato, Sherry, que no puede ver, tropieza con el vaso en un ademán que empuja el vaso hacia el fregadero. Se hace añicos, y puede pasar tres o cuatro semanas buscando los restos. Se topa con ellos como si fueran astillas.

Es esto a lo que ella se enfrenta. Si las personas que vienen a su apartamento nunca han estado ahí antes, puede verse en la necesidad de enseñarles diciéndoles: "Por favor no entren en mi cocina. Es imposible y es tedioso decirles por qué. No terminaría nunca. Tendría que explicar que una vez que empiecen me podrían generar un infierno para las próximas tres o cuatro semanas. Perderé cosas. Estarán ahí a plena vista. Solo que nada está a plena vista. Y si lo cambian de lugar me garantizan el proyecto de tener que encontrarlas. ¿Dónde diablos está el salero?”. Y así, no está preparada para tratar a sus invitados como si fueran ciegos novatos, para enseñarles lo que podría ser la ceguera en los lugares de trabajo donde ella tiene que desarrollar sus tareas.

La pericia de Sherry como etnógrafa y como analista de sus asuntos consiste en esto: por la fiesta y por los usos de su cocina, convirtió sus iniciativas en acciones irremediablemente instruidas. En esto encontramos las cosas misteriosas en las que pueden consistir las instrucciones. Por ejemplo, ella no ve que desde el otro lado de la habitación le dirigen una mirada. Más tarde le dicen que alguien se ofendió y se sintió desairado porque nunca le sirvieron la bebida que pidió. Nuestras preguntas: ¿Cuáles son los orígenes locales de la ofensa imaginaria? ¿Por qué señalar que la ofensa era imaginaria? De este modo Sherry se ha convertido en instructora. 


\section{IV.3. La máquina de café9}

Junto al termo de café que hay colocado en la cafetería del campus norte, Helen nos enseñó algo de lo cual Merleau-Ponty podría también haber estado hablando en Lo Visible y lo Invisible cuando habló del "ser salvaje... y su relación con... Gebilde, con la 'lógica' que producimos". ${ }^{10}$

Durante la pausa del mediodía hay una aglomeración en torno al termo de café. Helen evitaba esa área y no podíamos persuadirla de acompañarnos a tomar un café. "Por favor ven con nosotros así podemos ver qué cosa es tan terrible". "¡De ningún modo!" ¿Qué era tan terrible?

Cerca del termo de café se da una "aglomeración interaccional local". La gente se amontona alrededor del termo de café. Pregunta: ¿cómo se organizan para que "el siguiente" para el café se realice como turno, fluidamente, sin demoras, de manera calculada, sin accidentes, tumbos, derrames, disputas, ni conflictos?

Helen nos enseñó a ver y examinar los contrastes organizacionales entre la aglomeración interaccional local como procedimiento de servicio y el trabajo de una cola bien formada. En una cola bien formada uno tiene un lugar para ser atendido y la gente se ordena a sí misma "respecto del que atiende" para mostrar en su ubicación que existe un orden de servicio. El orden de servicio es visible en la fila aparente.

Pero junto al termo de café Helen no podía participar de la realización en curso de exhibir el orden de servicio. Sin embargo, se estaba logrando un orden de servicio: consistentemente, recurrentemente, uniformemente, establemente, pese al movimiento del personal, básicamente personas que habían sido parte de la aglomeración.

¿Cómo, exactamente?

Para Helen, por su ceguera nocturna congénita, la pregunta no era ¿algún modo? Sino en y como detalle local, encarnado, in vivo, de las posiciones, orientaciones corporales, ubicaciones, alcance rítmico y simultáneo, etc., simplemente ¿qué modo? En cada caso real, ¿exactamente cómo se hacía el trabajo de atender al próximo? Ella señaló que únicamente si uno se acercaba, de modo que alli uno pudiera llegar a ser parte del intercambio de sutiles cambios corporales y miradas simultáneas sin decir una palabra, y de ese modo se establecía allí una historicidad localmente confinada y únicamente disponible localmente, con la cual, por ser parte de esa historia, solo así uno podía ver exactamente ¿quién estaba antes, exactamente quién estaba después, quién después de ese y dónde estaba yo? Eso requería que uno pudiera ver sin hablar. Porque si uno tenía que hablar, inmediatamente se airearían, se descubrirían y se revelarían todo tipo de motivos "incongruentes" e "inapropiados" en y como parte de la petición.

Por su discapacidad, Helen solo podía llegar a los alrededores de la aglomeración, porque los alrededores no estaban cerca de los "lugares" locales donde estas historias se producían en, acerca de y en los que consistían esas historias, observablemente visibles, evidentes para todos. Solo cuando Helen fuera parte de su producción podría estar segura de qué podría parecer un siguiente "en la fila", dado que no había fila manifiesta. No había fila que ver. Aunque había un

Si bien Garfinkel denomina esta sección como La máquina de café, en ella se habla de la situación producida alrededor de un termo de café, lo cual implica una distinta aglomeración de interacción local [N. del T.]

10 Merleau-Ponty, The Visible and the Invisible, 170. 
orden propio de servicio observable (evidente para todos), ese era idéntico al orden de servicio observable (evidente para todos) producido y administrado.

Helen nos dijo que cada vez que lo había intentado había salido humillada. La gente la reprendía: ¿por qué empujas? O: alguien quiere mucho ese café. O: ¡estoy antes que tú! Y eso porque sus ojos no le permitían las delicadezas, no de empujar a los otros, sino de casi empujarlos. Si uno empujaba entonces eso motivaba un llamado de atención.

Nos decía: “¿Qué querían que hiciera? ¿Explicar? No parezco ciega, pero lo soy. Soy legalmente ciega. No tengo visión periférica. Tengo que seguir la multitud con barridos, y eso no alcanza".

\section{Podemos hacerlo de nuevo: siguiendo instrucciones como la familiaridad alcanzable de los detalles}

En cada uno de estos casos había algo que hacer y algo que aprender. Lo que había que aprender giraba en torno a, iluminaba, revelaba algo en y a partir de las instrucciones y el seguimiento in vivo de instrucciones como detalle, como trabajo de detalle. Eso no estaba disponible de ninguna otra manera más que en y a partir de la coherencia lograda de hacer exactamente eso en detalle. No en principio, no conforme a una regla, no como actores, no para satisfacer el privilegio del teórico de ocuparse de un fenómeno empírico teóricamente importante, no para resolverle al analista un problema empírico teóricamente importante. Sino exactamente en este lugar, exactamente en esta cocina, exactamente junto a este termo de café, exactamente en este jardín. Cuando digo "al detalle" quiero ser muy duro con eso. No es solo "al detalle". Es en la alcanzable familiaridad que puede realizarse en el detalle, disponible por la realización encarnada, para nuevamente, para cada siguiente primera vez, en la lograda ecceidad completa e inevitable del fenómeno y con sus contingencias, y realizado para iluminar y para volver problemática esta increíble cosa organizacional en la cual consisten las realizaciones encarnadas transparentes: el común y corriente "podemos hacerlo de nuevo". No solo yo, sino nosotros. Y de manera observable y explicable [accountable]. Y no solo podemos hacer de nuevo lo común y corriente y de manera explicable, sino también instructivamente.

Esta increíble familiaridad lograda del proyecto, disponible en y como el cuerpo de acción in vivo realizado localmente, en trans-curso, hecho de modo evidente para todos (observablemente) para concordar con su carácter observablemente (evidentemente) instruido. De eso permítanme hacer una propuesta reciente a la cual le han comenzado a prestar atención algunos del grupo que están haciendo estudios etnometodológicos, particularmente en los estudios sobre las ciencias naturales. Y esa propuesta es: en términos generales, el logro maravilloso, el logro técnico en las ciencias sociales, y su activo, es que en su inquietud por las acciones ordinarias la meta, el logro, el ideal, el activo, es ser capaz de proporcionar las propiedades esenciales invariantes de esas acciones; digamos, brindar las representaciones genéricas de esas acciones con las cuales encontrar en el acontecimiento real, lo que es observablemente el caso y recurrentemente demostrablemente también. Estos son los activos y el logro: las propiedades 
invariantes formales, analíticas y esenciales de la acción ordinaria son dadas designando y administrando representaciones genéricas de esas actividades; cualesquiera sean las actividades. Se reclama jurisdicción universal. No sin derecho ni sin razón. Y no sin ofrecer resultados bajo los auspicios de bienes empíricos científicamente observables.

Las investigaciones etnometodológicas han encontrado realizaciones mundanas de acciones ordinarias. Las representaciones genéricas no pueden revelar estos fenómenos. En vez de eso, en y a partir del trans-curso del flujo de trabajo, y sin abandonar el carácter endógeno del flujo de trabajo, todo aquello en lo que pudiera consistir lo genérico y lo trascendental y lo reproducible y lo comparable se encontraría allí como lo realizable que hace que eso parezca de tal modo.

Las personas en la máquina del café pueden "administrar" los turnos de una manera visible que revela, en la existencia endógena en curso de cada próxima taza in vivo, un orden de servicio en y a partir de la coherencia y el conocimiento de detalle. Supongamos que cualquiera de $-\mathrm{y}$ todos - los maravillosos tópicos del orden que hemos heredado en nuestras ciencias sociales como garantías recibidas de la historia intelectual - por ejemplo, los tópicos de la lógica, el sentido, el método, la razón, la acción racional, el orden, la temporalidad, el espacio, el lugar, la ubicación, la conciencia, la evidencia, la observación, la prueba, la demostración, la recopilación, la comparación-, supongamos que esos tópicos se encuentran en y a partir de los funcionamientos locales de las cosas organizacionales ordinarias: el termo de café, la cola formada, cruzar la calle, jugar al ajedrez, la disponibilidad en la calle en un ademán rápido: “¿Dónde está la panadería?" (Apuntando con la barbilla): "Allí".

Más aún, supongamos que la generalidad, la disponibilidad de las grandiosas propiedades genéricas realizadas de las actividades cotidianas se encuentran in vivo en y a partir del carácter endógeno de ese curso de acción que se está haciendo de nuevo, en y a partir de una familiaridad tal de sus detalles como para brindar ahi por todo lo que las representaciones genéricas han clamado como victorias y logros del trabajo de las ciencias naturales.

Llevémoslo un paso más lejos. Supongamos que en los laboratorios donde las ciencias naturales están haciendo los maravillosos logros de, digamos, métodos que son indiferentes a, e independientes de, quienes los practican; el carácter trascendental de los resultados de la ciencia natural es tal que encuentra sus "bases", sus "fundamentos", es decir, que encuentra su carácter examinable e instruible en esto: aquí, exactamente en este lugar, exactamente con este equipo, exactamente con nuestro grupo local vamos a ajustar la maquinaria y los informes publicados para asegurar localmente que exactamente nuestro grupo, en nuestro taller, hagamos que acontezca de nuevo el fenómeno.

Admitiendo estas suposiciones, entonces podría ser que los etnometodólogos hayan encontrado una cuestión realmente maravillosa que las ciencias naturales sin mencionar las ciencias sociales- demasiado rápidamente, quizás, han adaptado a los dispositivos que hemos denominado como el orgullo de la teorización general. Que lo que podrían haber encontrado son las grandes cuestiones que se plantean al aunar lo que el detalle podría ser en sus vínculos con la estructura. En las ciencias naturales se sabe que uno no puede tener lo uno sin lo otro. La cuestión es: pero exactamente cómo en los lugares de trabajo se está haciendo ese vínculo 
de modo tal que detalle y generalidad, acción encarnada, oficio, descubrimientos y resultados, en su relevancia mutua, estén irremediablemente amarrados como realizaciones locales.

Eso sería un posible ¿Y qué? Al encontrarse con el llamado carácter radical de las instrucciones, es decir, lo que podría haber en las instrucciones a lo que los métodos clásicos no tienen acceso y no han tenido acceso. No lo han planteado como un motivo de asombro. Los sociólogos, sin embargo, así como otros en las ciencias sociales, han encontrado eso como motivo de asombro. El motivo de asombro no es nada menos que la sociedad que nos es familiar. Los milagros de la sociedad que nos es familiar como el trabajo local consistente en esto: la gente que vive sus vidas ordinarias están realizando al hacerlo todo aquello que los tópicos magnificentes de la lógica, el sentido, el método, el orden, el mundo, lo real, y la evidencia siempre pretendieron ser.

Es posible, tal como Egon Bittner sugirió alguna vez, que los griegos hayan comprendido la acción racional y la razón antes que otros y que desde entonces todas estas realizaciones se perdieran de vista. Supongamos que la gente vive así. Supongamos que la sociedad ordinaria es de este tipo: con las maneras ordinarias en que la gente vive sus vidas juntas se ocupa de la producción endógena de estos fenómenos de orden, sentido, método, evidencia, prueba, discurso claro y así sucesivamente en y a partir de la única competencia localmente disponible de los objetos organizacionales más ordinarios del mundo, de las realizaciones familiares de sus vidas conjuntas comunes y corrientes.

Especificar estos supuestos en un catálogo de investigaciones del mundo real: a eso se dedica y se puede dedicar la etnometodología. 